\title{
Competitividade do complexo cafeeiro: uma análise a partir do market share e das vantagens comparativas simétricas
}

\author{
Vanderlei José Sereia ${ }^{1}$ \\ Márcia Regina Gabardo da Camara² \\ João Amilcar Rodrigues Anhesini ${ }^{3}$
}

Resumo: O objetivo deste artigo é analisar o comportamento dos principais indicadores de comércio exterior do complexo cafeeiro brasileiro entre 1990 e 2007. O Brasil é o maior produtor e exportador mundial de café e seu maior rival internacional é o Vietnã. O problema a ser estudado trata da evolução da competitividade - ganhos e perdas - do café brasileiro no período. O estudo discute os fundamentos econômicos sobre o comércio internacional, os indicadores internacionais de competitividade e caracteriza a dinâmica do complexo cafeeiro brasileiro. O problema a ser estudado é a evolução da competitividade, de forma a verificar ganhos e perdas de participação no comércio exterior, a partir de indicadores de comércio. Os procedimentos metodológicos utilizados para verificar a existência de vantagens e analisar os indicadores de comércio exterior são o modelo Constant Market Share e as vantagens competitivas reveladas simétricas (CRVS) do café brasileiro (verde, torrado, solúvel e especial) em relação aos países concorrentes. Discutem-se as barreiras às importações impostas ao café brasileiro pelos países importadores e as possíveis políticas públicas e privadas favoráveis à competitividade das exportações de café. $\mathrm{O}$ artigo verifica a existência de vantagens e os principais indicadores de comércio exterior sinalizam a expansão das exportações. $\mathrm{O}$ estudo conclui que o complexo cafeeiro é competitivo, especializado na exportação de café verde e tem baixa participação nos mercados de café torrado, solúvel e bebidas que contém café.

Palavras-chave: comércio internacional; competitividade; exportação de café. JEL: F10; F17; F19.

1 Doutorando pela Universidade Nove de Julho (Uninove). Professor titular do Departamento de Economia, Universidade Estadual de Londrina (UEL). E-mail: sereia@uel.br

2 Doutora em Economia pela Universidade de São Paulo (USP). Professora do Departamento de Economia, Universidade Estadual de Londrina (UEL). E-mail: mgabardo@sercomtel.com.br

3 Mestrando em Economia na Universidade Estadual de Londrina (UEL). E-mail: joaoamilcarr@hotmail.com 


\title{
Competitiveness in the cofee industry: an analysis from the market share and simetric revealed comparative advantage
}

\begin{abstract}
The aim of this paper is to analyze the behavior of the main indicators of foreign trade in Brazilian coffee industry between 1990 and 2007. Brazil is the largest producer and exporter of coffee and Vietnam is the major rival in international market. The research problem to be studied is the evolution of competitiveness of Brazilian coffee, in order to verify gains and losses in foreign trade. The study discusses the fundamentals international trade, international competitiveness indicators and characterized the dynamics of Brazilian coffee complex. The research objective is to verify the existence of competitive advantage in exports of coffee complex. The methodological procedures used to verify the advantages and analyze the indicators of foreign trade are the Constant Market Share model and revealed symmetric competitive advantage (RSCAs) of Brazilian coffee (green, roasted, soluble and special) in relation to competing countries. We discuss the import barriers imposed on Brazilian coffee by importing countries and the possible public and private policies conducive to competitiveness of exports of coffee. The article notes that there are advantages and the main indicators of foreign trade indicate the expansion of exports. The study concludes that coffee is competitive and specialized in the export of green coffee and has low participation in the markets for roasted coffee, soluble and drinks containing coffee.
\end{abstract}

Key-words: international trade; competitiveness; exportations coffee.

JEL: F10; F17; F19.

\section{Introdução}

O interesse pelo conceito de cadeia produtiva é recente e se faz importante para o estudo e compreensão da produção agrícola e o gerenciamento nas suas diversas dimensões - social, econômica, política, tecnológica, biológica, entre outras. A coordenação das cadeias tem sido o foco de muitos estudos de agribusiness, em particular para as cadeias expostas à competição internacional e às crescentes pressões dos consumidores. A relevância deste estudo se verifica em função da crescente participação do café na balança comercial e nas exportações do agronegócio brasileiro, em função de ter incorporado tecnologia agrícola e qualidade ao produto final tornando as exportações de café mais competitivas internacionalmente. 
O Brasil é o maior produtor e ofertante mundial de café arábica e tem garantido a manutenção e o crescimento da participação no mercado internacional devido ao custo de produção mais baixo que seus concorrentes. Além do custo de produção, a expansão do mercado de cafés especiais também é um fator determinante da competitividade. Sendo assim, a qualidade, os serviços pré e pós-venda, a capacidade para modificar especificações adaptando-se rapidamente às necessidades do consumidor, a baixa quantidade de defeitos, o marketing e a capacidade para concorrer em prazo de entrega representam a base da competitividade nos mercados mundiais.

O Brasil se tornou um grande produtor mundial de café com destaque para as exportações, se colocando a frente do Vietnã e Colômbia, outros grandes exportadores. O problema a ser estudado é a evolução da competitividade, de forma a verificar ganhos e perdas de participação no comércio exterior, a partir de indicadores de comércio exterior. No ano de 2009, o país exportou cerca de um terço de sua produção, alcançando a marca de 30 milhões de sacas. Neste mesmo ano, segundo informe do Conselho dos Exportadores de Café (Cecafé, 2010), o país ampliou seu domínio no mercado mundial, conquistando cerca de $30 \%$ das vendas totais do grão, sendo que a variedade com maior volume comercializado foi o café arábica, uma vez que este apresenta maior qualidade e maior valor agregado.

As barreiras tarifárias ao café industrializado (solúvel e torrado e moído) têm contribuído para a participação decrescente das exportações brasileiras no mercado internacional após 1993 (Nishijima; Saes, 2008). A indústria de solúvel está voltada ao mercado externo e é prejudicada pelo aumento da produção de café robusta na Ásia e pelas barreiras tarifárias na União Européia, além da questão tributária.

Estudos anteriores concentraram-se ou no mercado de café solúvel e a existência de barreiras ao produto brasileiro (Nishijima e Saes, 2010, 2008; Saes e Nakazone, 2002). O presente estudo inova ao destacar a partir do modelo Constant Market Share e das vantagens competitivas reveladas simétricas a competitividade externa dos principais produtos do complexo cafeeiro brasileiro.

O objetivo geral do artigo é analisar os indicadores de comércio exterior e a evolução da competitividade das exportações do complexo cafeeiro brasileiro entre 1990 e 2007. Os objetivos específicos realizam a discussão das características da produção e o comércio do complexo cafeeiro; o cálculo das taxas de crescimento das exportações mundiais, brasileiras e o market share; e a análise das fontes de crescimento do mercado mundial, da composição da pauta e destino das exportações, além de determinar a competitividade das exportações de café verde, solúvel e torrado brasileiro e das bebidas de café; e, finalmente, o cálculo das vantagens comparativas simétricas para o café brasileiro. 
O modelo Constant Market Share proposto por Leamer e Stern (1970) desenvolvido para explicar o crescimento e a competitividade das exportações de uma nação, tem sido empregado para explicar o desempenho das exportações de setores econômicos e produtos. Carvalho (1995) utilizou o modelo CMS para explicar o crescimento e a competitividade do complexo agroindustrial brasileiro e mais tarde Stalder (1997) empregou-o para explicar o desempenho das exportações de açúcar. A partir de então, vários autores passaram a empregar o modelo para explicações do desempenho e a competitividade das exportações de produtos por país e entre os países.

No presente trabalho apresenta-se uma discussão sobre as exportações dos principais tipos de café (verde, solúvel, torrado e bebidas) e analisa-se o crescimento das exportações pela decomposição das fontes de crescimento e mensuramos seus efeitos para explicar a competitividade do café brasileiro. O desempenho e a competitividade do complexo cafeeiro brasileiro foram medidos pelos modelos modelo CMS e visando a confirmação de resultados, compara-se o modelo de vantagem comparativa revelada simétrica (VCRS); de acordo com a teoria, os resultados foram equivalentes.

Os procedimentos metodológicos envolvem os modelos Constant Market Share e Vantagens Comparativas Reveladas Simétricas. O artigo está estruturado em 6 partes: introdução, revisão de literatura de comércio internacional e competitividade, mercado de café, metodologia, resultados e conclusão.

\section{Comércio internacional e competitividade}

O comércio entre as nações ativa o processo competitivo através da busca por maiores vantagens, ou seja, o fluxo internacional de mercadorias depende dos preços relativos dos fatores de produção (trabalho, matérias-primas, infra-estrutura e capital), podendo ser influenciado pelas diferenças nas dotações de fatores, tecnologia disponível, economias de escala, padrões de consumo e pela estrutura de mercado.

A análise da competitividade e dos determinantes do comportamento e do crescimento das exportações tem origem no princípio das Vantagens Comparativas Relativas de Ricardo. Segundo a teoria ricardiana, o comércio internacional ocorre quando o tempo de trabalho necessário para produzir pelo menos um produto for inferior àquele que vigora em uma nação rival no exterior. $\mathrm{O}$ comércio aumenta o mercado para os produtos produzidos domesticamente e permite o aprofundamento da divisão do trabalho, contribuindo para aumentar a riqueza das nações. (Carvalho, 200o) Ricardo (1982) afirma que o comércio internacional e os ganhos do comércio são possíveis devido à diferença de custos relativos ou comparativos derivados da produtividade do trabalho. A lei das vantagens comparativas também é conhecida como a lei dos custos comparativos (Salvatore, 2000). 
As condições de oferta, que dependem de sua dotação de terra, mão-de-obra e capital, bem como de sua tecnologia, diferem de um país para outro, levando às diferenças de preços entre os países. De acordo com Williamson (1989), existem respostas compatíveis com o modelo de um só fator de Ricardo: as diferenças poderiam ser causadas por condições climáticas ou diferentes níveis de tecnologia.

As teorias modernas de comércio internacional são baseadas no custo comparativo - oportunidades. Segundo Hecksher e Ohlin, as diferenças de custos de produção de uma mesma mercadoria de uma nação para outra são conseqüências de várias circunstâncias, tais como: custos dos insumos, proporção dos fatores de produção (natureza, trabalho e capital), imobilidade da mão-de-obra, e dificuldades na transferência dos fatores de produção de um país para outro.

O teorema de $\mathrm{H}-\mathrm{O}$ afirma que cada país se especializa e exporta o bem que requer utilização mais intensiva de seu fator de produção abundante (Carvalho, 2000). Esse modelo mostra que as vantagens comparativas são influenciadas pela interação entre os recursos da nação (a abundância relativa dos fatores de produção) e a tecnologia da produção (que influencia a intensidade relativa com a qual fatores diferentes de produção são usados na produção de bens distintos) (Krugman e Obstfeld, 1999). Assim, o teorema de H-O também é chamado de teoria das proporções dos fatores ou das dotações de fatores.

$\mathrm{Na}$ teoria de $\mathrm{H}-\mathrm{O}$, segundo Salvatore (2000) dada a distribuição de renda e as preferências dos consumidores, o comércio de bens é uma forma indireta de comercializar os fatores de produção. O Teorema de Hecksher-Ohlin-Samuelson (H-O-S) enuncia que o comércio internacional equaliza os preços dos fatores de produção entre as nações. Com o comércio cada país se especializa na produção do bem em que possui vantagem comparativa (intensivo em fator de produção abundante, mais barato). $\mathrm{O}$ aumento da produção estimula a demanda pelo fator abundante e eleva seu preço. Enquanto houver diferenças entre os preços relativos dos fatores (trabalho e capital), o comércio se expande.

O teorema de Stolper-Samuelson revela que os preços dos fatores dependem do preço das mercadorias que produzem. Segundo o teorema, o comércio beneficia o fator de produção abundante em detrimento do fator escasso de cada país. O pleno emprego e a equalização do preço dos fatores garantem que o fator de produção abundante se beneficie com o comércio, possibilitando a redistribuição da renda. De acordo com Williamson (1989), os detentores do fator de produção escasso podem aumentar sua renda real em termos absolutos através da proteção restritiva de importações, mesmo que a sociedade como um todo perca. A teoria de Hecksher-Ohlin (H-O) pressupõe retornos constantes à escala, mas o comércio internacional pode se basear também em retornos crescentes à escala. Quando as economias de escala se aplicam no nível das indústrias em vez de no nível das firmas individuais, elas são chamadas de economias externas. 
O debate sobre concorrência imperfeita (monopolística) é o campo mais relevante para a discussão do comércio internacional no período recente porque a maior parte do comércio mundial ocorre não entre países que se especializam na produção de produtos distintos, mas entre países que comercializam os mesmos produtos. Sob condições de concorrência imperfeita, há incentivos para que os governos subsidiem a exportação ou pesquisas para o desenvolvimento de novos produtos a serem exportados no intuito de obter lucros mais altos em mercados estrangeiros.

O comércio e o fluxo internacional de mercadorias dependem dos preços relativos dos fatores de produção (trabalho, matérias-primas, infra-estrutura e capital), e é influenciado pelas diferenças nas dotações de fatores, tecnologia disponível, economias de escala, padrões de consumo e pela estrutura de mercado. Neste contexto as economias se diferenciam pela eficiência no emprego dos fatores que resultam em vantagens competitivas e determinam o seu padrão de competitividade.

A maioria dos estudos trata a competitividade como um fenômeno diretamente relacionado às características de desempenho ou de eficiência técnica e alocativa apresentadas por empresas e produtos e a considerar a competitividade das nações como a agregação desses resultados. A competitividade revelada é vista como um desempenho e é expressa pela participação no mercado (market-share) alcançada por uma firma em um mercado em certo momento do tempo. A competitividade é uma variável ex-post que sintetiza os fatores preço e não-preço (qualidade de produtos e de fabricação, habilidade de servir ao mercado, capacidade de diferenciação de produtos) (Ferraz; Kupfer; Haguenauer, 1995).

Conforme já destacado, a análise da competitividade e dos determinantes do comportamento e do crescimento das exportações tem origem no princípio das Vantagens Comparativas Relativas de Ricardo. As primeiras discussões surgem no âmbito da Teoria da Organização Industrial no Modelo EstruturaConduta-Desempenho. As vantagens competitivas são conquistadas ao nível da firma e as forças competitivas determinantes da atratividade estrutural no longo prazo de um setor são: intensidade da rivalidade capitalista, a existência de ameaça de novos entrantes, as ameaças de substitutos, o poder de negociação com compradores e o poder de negociação com fornecedores.

Segundo Porter (1986), o fortalecimento da posição competitiva depende da implementação de estratégias genéricas: liderança no custo total, diferenciação e enfoque. No agribusiness, a liderança em custo é essencial, pois boa parte dos produtos é classificada como commodities, que requerem amplo volume de operação para obtenção de ganhos nas economias de escala e de escopo e, assim, reduzir os custos unitários de produção e distribuição. A diferenciação de produtos e serviços através da pesquisa e desenvolvimento, tecnologia e inovação e ações de marketing, vendas e distribuição deve ampliar a taxa de 
lançamento de produtos e serviços, oferecendo novos produtos e agregando diferenciais às commodities tradicionais. Quanto ao enfoque, as empresas devem escolher se vão atuar orientadas para um alvo amplo (mercado mundial ou nacional) ou estreito (mercados locais ou regionais). As estratégias de enfoque podem ser aplicadas em um ou mais processos, como suprimento de insumos ou matérias-primas, a produção agropecuária ou industrial, e as atividades de marketing, vendas e distribuição (Wedeckin, 2002).

No Brasil, a infra-estrutura de pesquisa e desenvolvimento de novas variedades de sementes, novas técnicas de cultivo e manejo de safras contribui para a competitividade da agroindústria. O complexo agroindustrial do café apresenta capacidade competitiva, níveis elevados de eficiência produtiva e excelente desempenho no comércio exterior. Saes e Nakazone (2002) destacam no estudo da cadeia produtiva de café prevalecem ações que reforçam posições competitivas já alcançadas, sobretudo no que tange à agregação de valor nas exportações (via diferenciação de produtos) e no apoio à internacionalização de empresas para melhorar e ou controlar a distribuição nos mercados externos (via marcas próprias ou redes).

\section{Organização e comércio do café}

O mercado de café tem uma longa história de regulamentação no Brasil e fora dele. No Brasil, havia a ação do Instituto Brasileiro do Café (IBC) e no mercado internacional, a presença da Organização Internacional do Café (OIC), órgãos criados nos anos 1950 (Bragança, 2000). Entre 1950 e 1990 ano da extinção do IBC - segundo Saes e Nakazone (2002), no plano interno a regulamentação permite coordenar o sistema cafeeiro - produção rural, indústria de transformação e distribuição/consumo. Como líder do mercado produtor de café, o Brasil desempenha um papel central no sucesso da política de sustentação dos preços no mercado mundial, mas em muitos momentos, os acordos foram efetivados porque o país se sujeitou a reduzir sua participação, firmando-se como ofertante residual, isto é, retendo os estoques.

Os resultados de 50 anos de política de restrição da oferta incluem a queda de participação de mercado e a imagem sedimentada no mercado internacional de que o café brasileiro tem uma qualidade média e serve apenas para formar blends. Segundo Saes e Nakazone (2002), a competitividade brasileira tem sido afetada pelo diferencial de preços entre o café brasileiro e os cafés suaves, considerados de maior qualidade. Há o crescimento da participação do café robusta no mercado internacional, particularmente do Vietnã, que aliado às novas tecnologias na formação de blends torna-se um substituto próximo do café brasileiro, ou seja, o café brasileiro torna-se extremamente elástico.

No Brasil, após a extinção do IBC, instala-se oficialmente a "Comissão Especial da Auto Gestão do Funcafé" em 1996, com a incumbência de institucionalizar 
um novo modelo de gestão da cafeicultura brasileira e é criado o Conselho Deliberativo da Economia Cafeeira (CDPC). Em 1999, cria-se o Conselho dos Exportadores de Café Verde do Brasil (Cecafé) que busca aumentar a margem do setor através da congregação e da representação das empresas que exportam café verde (Bragança, 2000).

\subsection{Barreiras às exportações do café brasileiro}

Bragança (2000) afirma que não há barreiras à entrada do café verde no mercado americano e europeu, pois são os principais destinos das exportações brasileiras e grandes exportadores mundiais de café processado. No caso do café torrado, a entrada no mercado internacional exige uma série de pré-requisitos que dificultam a exportação. Já para o café solúvel, existem barreiras tarifárias desiguais entre os países concorrentes.

O café solúvel brasileiro sofre barreiras tarifárias na União Européia (Nishijima: Saes, 2008). As indústrias dos países concorrentes ou são isentas das taxas de importação, sob alegação de uma política de cooperação ao combate do narcotráfico, ou são taxadas com uma menor alíquota, como no caso do México e Índia. Nishijima e Saes (2010) identificam queda no potencial de crescimento das exportações em função das barreiras impostas ao café solúvel brasileiro no período 1995 a 2003.

A indústria de torrefação e moagem brasileira foca o mercado interno; a inserção no mercado internacional é restrita, mesmo sendo equacionada a questão da perecibilidade do produto com a embalagem a vácuo. Entre 1970 e 1990, a indústria de torrefação se concentra nos países desenvolvidos. Segundo Saes e Nakazone (2002) o movimento de consolidação da indústria torrefadora internacional representa uma barreira à inserção das torrefadoras brasileiras nos mercados consumidores, mas as altas margens de lucros recebidas por elas podem viabilizar a exportação de café torrado moído brasileiro diretamente para o varejo internacional, mesmo na presença de altas tarifas cobradas sobre o produto na União Européia.

O estudo sobre as barreiras aos produtos e serviços brasileiros, realizado pela Embaixada do Brasil em Washington (2002), destaca as legislações e regulamentações adotadas pelos Estados Unidos, por motivo de segurança, como o Bioterrorism Act, iniciativas da alfândega, como "Advanced Cargo Manifests" e "Container Security Initiative", transformou-se em barreiras ao acesso das exportações de café brasileiro ao mercado americano. 


\subsection{Análise da evolução das exportações}

A cadeia agroindustrial do café constitui um dos setores importantes da economia brasileira pela sua expressiva participação na pauta de exportação e na geração de emprego e de renda e representa, no médio e no longo prazo, um dos principais produtos estratégicos para o país. A importância da cafeicultura brasileira pode ser visualizada pelo volume de produção e pelo consumo interno (Teixeira, 2000). O Brasil é o maior produtor mundial de café arábica, seguido da Colômbia, Guatemala, México e Indonésia. O Vietnã é o maior produtor mundial de café robusta. Os Estados Unidos, Brasil, Alemanha e Japão são os maiores consumidores. (ICO, 2010; FAO, 2010)

A trajetória do café no país reflete a dinâmica de sua inserção no cenário mundial (Ormond; Paula; Faveret Filho, 1999). O mercado internacional do café tem uma característica que o difere da maioria das outras mercadorias transacionadas entre os países, há fluxos de re-exportação por países não-produtores. A Alemanha é o principal re-exportador ou entreposto comercial; as estratégias de reexportação são basicamente de ocupação dos mercados intrablocos econômicos, facilitados pelas zonas de livre comércio e proximidades geográficas. Os compradores têm tradição de exigir qualidade da matéria-prima importada e podem deslocar as vendas, dificultando a conquista de novos mercados pelos países produtores como a reconquista dos mercados perdidos.

A Tabela 1 apresenta a participação dos principais blocos e regiões exportadores nos períodos de 1999/2003 e 2004/2007, e o destino e a participação das exportações. América do Sul (43,2\%) e o Leste da Ásia (19,5\%) vêm aumentando as suas exportações de café verde para atender a demanda industrial mundial em expansão para a produção de cafés finos e misturas especiais, que são exportados pelos países da União Européia (Alemanha, Itália, Espanha, França e Reino Unido) e do North American Free Trade Agreement (NAFTA). Brasil (25,7\%), Colômbia (13,7\%), Vietnam (10,9\%) e Indonésia $(4,9 \%)$, juntos respondem por mais de $50 \%$ do comércio mundial de café verde. (ICO, 2010; FAO, 2010 ; ABIC, 2010)

A União Européia (UE) e a European Free Trade Agreement (EFTA) são os maiores exportadores mundiais de café torrado (73,3\%), café solúvel (48,8\%) e bebidas que contém café (31,08\%); repassam café verde e com cascas, para os mercados regionais. Os principais países europeus exportadores de café solúvel são: Alemanha (20\%), Reino Unido (6,1\%), Espanha (5,0\%) e França (4,1\%). O mercado de café torrado é dominado pela Itália (20,6\%), Alemanha (16,7\%), Bélgica (9,0\%) e Suíça (7,2\%). 
TABELA 1. PARTICIPAÇÃO DAS EXPORTAÇÕES MUNDIAIS DO COMPLEXO AGROINDUSTRIAL DO CAFÉ NO PERÍODO DE 1999 A 2007

\begin{tabular}{|c|c|c|c|c|c|c|c|c|c|c|}
\hline \multirow{2}{*}{$\begin{array}{c}\text { Regiões/ } \\
\text { Blocos }\end{array}$} & \multicolumn{2}{|c|}{ Verde } & \multicolumn{2}{|c|}{ Solúvel } & \multicolumn{2}{|c|}{ Torrado } & \multicolumn{2}{|c|}{ Bebidas } & \multicolumn{2}{|c|}{ Grãos Casca } \\
\hline & 99-03 & 04-07 & 99-03 & 04-07 & 99-03 & 04-07 & 99-03 & 04-07 & 99-03 & 04-07 \\
\hline $\begin{array}{l}\text { União } \\
\text { Européia }\end{array}$ & 7,1 & 9,1 & 42,5 & 44,5 & 65,5 & 59,4 & 17,3 & 29,8 & 16,2 & 1,3 \\
\hline EFTA & - & 0,1 & 3,2 & 4,3 & 2,8 & 16,9 & - & 1,2 & - & - \\
\hline NAFTA & 7,3 & 1,2 & 9,5 & 3,9 & 19,4 & 13,9 & 14,3 & 11,6 & 11,3 & 0,8 \\
\hline $\begin{array}{l}\text { Leste } \\
\text { Europeu }\end{array}$ & - & 0,0 & 6,3 & 8,9 & 5,4 & 6,0 & 6,8 & 8,0 & - & - \\
\hline Mercosul & 22,3 & 29,4 & 11,2 & 11,5 & - & 0,7 & - & 0,8 & - & 0,6 \\
\hline $\begin{array}{l}\text { América } \\
\text { Central }\end{array}$ & 18,2 & 16,5 & - & 2,6 & - & 0,7 & - & 4,3 & - & - \\
\hline $\begin{array}{l}\text { Tigres } \\
\text { Asiáticos }\end{array}$ & 5,0 & 0,4 & 11,4 & 7,2 & 1,2 & 0,7 & 3,8 & 2,8 & 4,3 & 0,1 \\
\hline Ásia & 14,1 & 19,5 & - & 7,4 & - & 0,5 & 21,3 & 2,3 & - & 0,5 \\
\hline $\begin{array}{l}\text { Oriente } \\
\text { Médio }\end{array}$ & - & 0,2 & - & 0,4 & 2,8 & 0,5 & 9,7 & 19,2 & 19,2 & 0,9 \\
\hline Oceania & 1,5 & 1,2 & - & 0,6 & - & 0,4 & 14,3 & 4,0 & - & - \\
\hline $\begin{array}{l}\text { América } \\
\text { do Sul } \\
\text { (s/ Mercosul) }\end{array}$ & 17,6 & 13,8 & 7,0 & 6,4 & - & 0,3 & - & 6,7 & 17,3 & - \\
\hline África & 11,6 & 8,8 & 3,7 & 2,4 & - & 0,1 & 24,9 & 9,3 & 31,6 & 95,6 \\
\hline
\end{tabular}

Fonte: elaborado a partir dos dados da FAO, 2010.

O NAFTA tem mercado diversificado de importação e exportação de produtos do complexo cafeeiro, destacando-se a exportação de café torrado e bebidas que contém café. Os Estados Unidos é o principal exportador de café torrado (10,7\%), café solúvel (3,2\%) e bebidas com café (11,8\%). (tabela 1)

As exportações brasileiras de café verde e café solúvel apresentam vantagem comparativa em todos os índices aplicados, conforme a Tabela 2, com destaque para o melhor desempenho do café verde e solúvel. Essa vantagem do café verde e solúvel corrobora os resultados do modelo Constant Market Share.

A indústria cafeeira brasileira tem adotado estratégias para reagir às ações das transnacionais alimentícias e tarifas discriminatórias impostas ao café brasileiro solúvel (Nishijima; Saes, 2010). Mas as barreiras associadas 
à vantagem competitiva sustentável derivada de arranjos de parcerias industriais têm contribuído para que a indústria européia mantenha sua liderança - fruto da aproximação de fabricantes de café e equipamentos especiais para o uso e preparo do café, como as máquinas de café expresso em grãos torrados e saches de café moído (Tabela 1).

As exportações brasileiras concentram-se em café verde e solúvel - o verde representa mais de $86 \%$ do total exportado. A produção de café torrado e moído é voltada para o mercado interno - acima de 95\%. A grande vantagem do Brasil em relação a seus concorrentes reside no fato de o país produzir todas as qualidades de café, que são suficientes para atender a qualquer demanda.

O destino das exportações brasileiras é apresentado na Tabela 2. Os principais importadores do café brasileiro são: Alemanha, Itália, Estados Unidos e Japão. Verifica-se a expansão da participação de mercados emergentes, como o Oriente Médio e EFTA e declínio na participação nos mercados asiáticos e Mercosul (ABIC, 2010; MDIC/AliceWeb, 2010).

TABELA 2. DESTINO E PARTICIPAÇÃO DAS EXPORTAÇÕES BRASILEIRAS DO COMPLEXO AGROINDUSTRIAL DO CAFÉ DE 1999 A 2007

\begin{tabular}{l|cc|c|c|c|c|cc}
\hline \multirow{2}{*}{ Regiões/Blocos } & \multicolumn{2}{|c|}{ Verde } & \multicolumn{2}{c|}{ Solúvel } & \multicolumn{2}{c|}{ Torrado } & \multicolumn{2}{c}{ Bebidas } \\
\cline { 2 - 10 } & $\mathbf{9 9 - 0 3}$ & $\mathbf{0 4 - 0 7}$ & $\mathbf{9 9 - 0 3}$ & $\mathbf{0 4 - 0 7}$ & $\mathbf{9 9 - 0 3}$ & $\mathbf{0 4 - 0 7}$ & $\mathbf{9 9 - 0 3}$ & o4-o7 \\
\hline Leste Europeu & 5,2 & 5,2 & 39,7 & 35,8 & 2,1 & 0,8 & 0,3 & 1,1 \\
\hline União Européia & 56,4 & 49,8 & 17,3 & 17,4 & 8,1 & 20,0 & 0,7 & 0,5 \\
\hline NAFTA & 19,7 & 19,8 & 18,6 & 15,1 & 45,5 & 64,8 & 0,8 & 0,8 \\
\hline Tigres Asiáticos & 9,5 & 9,4 & 13,7 & 9,9 & 13,4 & 5,1 & 92,3 & 73,0 \\
\hline Mercosul & 2,4 & 1,9 & 4,9 & 4,6 & 9,5 & 5,7 & 3,6 & 14,5 \\
\hline América do Sul* & 0,5 & 0,4 & 1,1 & 3,9 & 18,1 & 0,3 & 2,1 & 0,5 \\
\hline Ásia (s/ Tigres) & - & 0,4 & - & 3,4 & - & 0,3 & - & 1,6 \\
\hline EFTA & 1,9 & 7,5 & - & 2,9 & - & 0,8 & - & 1,4 \\
\hline Oriente Médio & 2,9 & 3,9 & 0,4 & 2,5 & 0,5 & 0,3 & - & - \\
\hline América Central & - & 0,4 & - & 2,2 & - & 0,8 & - & 6,4 \\
\hline África & 0,9 & 0,6 & 0,6 & 1,3 & 1,5 & 0,8 & - & - \\
\hline Oceania & - & 0,7 & 1,8 & 1,1 & 0,8 & 0,2 & - & - \\
\hline
\end{tabular}

Fonte: elaborado a partir dos dados da FAO e MDIC/SECEX, 2010. *(s/ Mercosul). 
A Tabela 3 destaca a concentração da demanda por café brasileiro, no café verde. Os principais mercados são a União Européia - Alemanha (20,7\%) e Itália (11,1\%) - NAFTA - Estados Unidos (17,9\%) - e tigres asiáticos - Japão $(8,5 \%)$. Estas regiões são responsáveis pela compra de aproximadamente 70\% das exportações de café verde no período de 2001-07, enquanto outros 16\% são comercializados no Leste Europeu, EFTA e Oriente Médio.

O mercado de café solúvel é diversificado com forte participação do Leste Europeu (35,8\%); os maiores países compradores são a Rússia (19,1\%) e Ucrânia (8,7\%). Na União Européia (17,4\%), os países que mais demandam são Alemanha $(6,4 \%)$ e Bélgica (2,3\%). No NAFTA, o principal comprador é os Estados Unidos (13,1\%) e na Ásia, destaca-se a demanda do Japão (5,9\%) (Tabela 3).

TABELA 3. PRINCIPAIS PAÍSES COMPRADORES DO CAFÉ BRASILEIRO NO PERÍODO DE 2004 A 2007

\begin{tabular}{|c|c|c|c|c|}
\hline Bloco/Países & Café Verde & Café Torrado & Café Solúvel & Bebidas \\
\hline União Européia & - & - & - & - \\
\hline Alemanha & 20,7 & - & 6,4 & - \\
\hline Itália & 11,1 & 17,1 & - & - \\
\hline Bélgica & - & - & 2,3 & - \\
\hline NAFTA & - & - & - & - \\
\hline Estados Unidos & 17,9 & 64,1 & 13,2 & - \\
\hline Tigres Asiáticos & - & - & - & - \\
\hline Japão & 8,5 & 5,0 & 5,9 & 42,1 \\
\hline Mercosul & - & - & - & - \\
\hline Argentina & - & 4,5 & - & 8,2 \\
\hline Uruguai & - & 2,1 & - & - \\
\hline Leste Europeu & - & - & - & - \\
\hline Rússia & - & - & 19,1 & - \\
\hline Ucrânia & - & - & 8,7 & - \\
\hline
\end{tabular}

Fonte: elaborado a partir dos dados da FAO e MDIC/SECEX, 2010. 
Os maiores compradores do café torrado brasileiro são Estados Unidos (64,1\%), Itália $(17,1 \%)$ e Japão (5,0\%). Entre os parceiros comerciais do Mercosul destacam-se Argentina (4,5\%) e Uruguai (2,1\%). As bebidas e essências de café brasileiras são direcionadas, preponderantemente, para o mercado do Japão (71\%), da Argentina (12,5\%) e o Chile (5,7\%) (Tabela 3).

O mercado mundial de café é muito competitivo, apresentando infra-estrutura de processamento difundida em todo o mundo. As tecnologias de processamento são bem conhecidas e estão concentradas em países com larga experiência no desenvolvimento de novas tecnologias de produtos e processos. A dificuldade de competir em mercados tradicionais estimula estratégias da agroindústria cafeeira brasileira e a busca de novos mercados. A tabela 2 apresenta o destino das exportações brasileiras. Verifica-se diminuição da participação nos mercados tradicionais, e crescimento da participação nos mercados emergentes. O desafio da indústria cafeeira brasileira reside na conquista do mercado do Leste Europeu e da China. (MDIC/AliceWeb, 2010; ABIC, 2010)

As exportações do complexo cafeeiro estão concentradas na exportação do café verde, que serve de matéria prima para as indústrias européias e americanas. As empresas nacionais precisam desenvolver estratégias que ampliem as possibilidades de criar novos produtos derivados do café, desenvolver parcerias na indústria cafeeira, ampliar mercados e a participação nos mercados tradicionais, para superar a concorrência européia. (MDI/ AliceWeb, 2010; ABIC, 2010).

\section{Metodologia}

O presente item apresenta dois modelos que permitem explorar a competitividade de comércio: Constant Market Share e Vantagens Comparativas Reveladas Simétricas.

\subsection{Constant Market Share (CMS)}

O método para avaliar a competitividade, o modelo Constant-Market-Share (CMS), permite identificar as causas do crescimento das exportações de café, comparando o desempenho do mercado exportador em relação ao mercado importador (Leamer; Stern, 1970). O modelo CMS atribui o crescimento das exportações, ao setor exportador; o suposto é que mantida a parcela de exportação do país, a variação constitui a competitividade. Para a análise de market-share, a década de 1990 e 2007 será subdividida em quatro períodos, trabalhando-se com valores médios: o primeiro período vai de 1990 a 1993, o segundo de 1994 a 1998, o terceiro de 1999 a 2003 e o quarto período de 2004 a 2007. 
O modelo CMS decompõe as fontes de crescimento das exportações e identifica os elementos determinantes do desempenho das exportações do complexo cafeeiro brasileiro. O país aumenta sua participação no comércio mundial e suas exportações crescem acima da média quando: a) estão concentradas em mercadorias cujas demandas crescem mais velozmente; b) são destinadas a mercado/países cuja demanda cresce relativamente mais rápido; c) estão se beneficiando de outros ganhos de competitividade, além dos mencionados.

O método atribui o crescimento favorável/desfavorável das exportações ao setor exportador, tanto na estrutura de exportações do país quanto em sua competitividade. O modelo supõe que, mantida a parcela de exportação do país, a variação verificada ocorre em função da competitividade, sendo que a decomposição do crescimento das exportações é feita de acordo com os seguintes fatores: a) crescimento do comércio internacional; b) composição da pauta de exportações; c) destino das exportações; d) competitividade, determinada pelo resíduo das demais. Atribui-se ao resíduo negativo o fracasso de manter-se no comércio e ao resíduo positivo o sucesso na ampliação da participação do comércio internacional.

O modelo permite a análise por componentes e pelo comportamento do produto no mercado de destino, indicando os mercados onde o país é mais competitivo. Embora se faça uso de séries passadas, o método CMS apresenta a possibilidade de serem feitas estimativas sobre o direcionamento e a concentração do setor exportador em produtos mais dinâmicos. Assim, o modelo CMS é expresso pela seguinte equação:

$$
\begin{aligned}
& V *_{. .}-V_{. .}=r V . .+\sum_{i}(r i-r) V i+\sum_{i} \sum_{j}(r i j-r i) V i j+\sum_{i} \sum_{j}(V * i j-V i j-r i j V i j) \\
& V *_{.}-V_{. .}=r V . .+\sum_{i}(r i-r) V i+\sum_{i} \sum_{j}(r i j-r i) V i j+\sum_{i} \sum_{j}(V * i j-V i j-r i j V i j)
\end{aligned}
$$

(a)

(b)

(c)

(d)

em que:

V.. = valor total das exportações de café brasileiro no período 1;

$\mathrm{V}^{*}$. . = valor total das exportações de café brasileiro no período 2;

$\mathrm{r}=$ incremento das exportações mundiais de café do período 1 para o período 2 .

$\mathrm{V}_{\mathrm{ij}}=$ valor total das exportações de café brasileiro, para o país j, período 1;

$\mathrm{V}^{*}{ }_{\mathrm{ij}}=$ valor total das exportações do café brasileiro, para o país j, período 2;

$\mathrm{r}_{\mathrm{ij}}=$ incremento das exportações mundiais de café para o país j do período 1 para o período 2. 
Os quatro efeitos diferenciados são relacionados a seguir, sendo os de (a) e (b) relacionados a fatores externos, e os efeitos (c) e (d) a fatores internos. Assim sendo: a) Efeito crescimento do comércio mundial - incremento observado se as exportações brasileiras tiverem crescido à mesma taxa de crescimento do comércio mundial. b) Efeito composição da pauta de exportação - mudanças na estrutura da pauta com concentração em produto com crescimento de demanda mais ou menos acelerado; indica que se as exportações mundiais do produto $i$ aumentam mais do que a média mundial para todas as mercadorias exportadas, $\left(r_{i}-r\right)$ é positivo. O efeito composição da pauta será positivo se as exportações brasileiras estiverem concentradas no produto de maior expansão ou quando a taxa de crescimento for superior à média mundial. c) Efeito destino das exportações - mudanças decorrentes de exportações de produtos para mercados de crescimento mais ou menos dinâmicos. Será positivo se o Brasil tiver concentrado suas exportações em mercados que experimentaram maior dinamismo no período analisado, e negativo se concentrado em regiões estagnadas. d) Efeito residual, representando a competitividade - que reflete a diferença entre o crescimento atual e o crescimento que teria ocorrido nas exportações do Brasil se tivesse sido mantido a parcela de exportação de cada bem para cada país. Significa que uma economia é competitiva na produção de determinada mercadoria quando consegue pelo menos se igualar aos padrões de eficiência vigentes no resto do mundo quanto à utilização de recursos e à qualidade do bem.

A diferença entre o crescimento das exportações verificadas pelo modelo CMS e o crescimento efetivo é atribuída ao efeito competitividade, e a medida desse efeito relaciona-se a mudanças nos preços relativos. Quando um país perde parcela no mercado mundial, o termo competitividade torna-se negativo e seus preços crescem diante dos preços dos competidores. Os produtos mais representativos do complexo cafeeiro são os seguintes: café verde, café torrado, café solúvel e bebidas com café.

As fontes utilizadas fora as estatísticas da MDIC/AliceWeb (2010) para as exportações brasileiras e os dados da $\mathrm{ICO}(2010)$ e $\mathrm{FAO}(2010)$ para as exportações e importações mundiais.

\subsection{Vantagens Comparativas Reveladas Simétricas para o complexo cafeeiro}

A inserção do índice de vantagem comparativa revelada simétrica (VCRS) explora a estabilidade conferida ao índice de vantagem comparativa revelada. O VCR apresenta uma assimetria quanto às dimensões das vantagens ou desvantagens comparativas reveladas: o índice VCR varia entre 1 e infinito, enquanto o índice VCRS varia entre o e 1. Desta forma: 
$\operatorname{VCRS}_{i j}=\frac{\left(\mathrm{VCR}_{\mathrm{ij}}-1\right)}{\left(\mathrm{VCR}_{\mathrm{ij}}+1\right)} \mathrm{VCRS}_{\mathrm{ij}}=\frac{\left(\mathrm{VCR}_{\mathrm{ij}}-1\right)}{\left(\mathrm{VCR}_{\mathrm{ij}}+1\right)}$

Na expressão 2, o $\mathrm{VCRS}_{\mathrm{ij}}$ representa o índice de vantagem comparativa revelada simétrica. Quando o resultado de $\mathrm{VCRS}_{\mathrm{ij}}$ varia entre -1 e o há desvantagem comparativa para o produto em estudo e quando o resultado se concentra entre o e 1 a vantagem comparativa é revelada. O VCRS foi aplicado aos dados de exportações brasileiras do complexo cafeeiro.

\section{Análise da competitividade do café brasileiro}

O presente item discute a competitividades das exportações brasileiras de café a partir dos resultados do modelo Constant Market Share e do modelo de Vantagens Comparativas Reveladas Simétricas.

\subsection{Análise dos resultados do modelo Constant Market Share para o complexo cafeeiro}

A aplicação do modelo CMS permitiu analisar a decomposição e a contribuição dos efeitos relacionados ao crescimento do comércio mundial, composição da pauta de exportações, destino das exportações e competitividade entre 1990 a 2007.

A Tabela 4 apresenta os resultados do modelo CMS, para o período de 1990 a 2007. O desempenho das exportações brasileiras do complexo agroindustrial do café é atribuído aos efeitos do crescimento do comércio mundial e da competitividade brasileira. Observa-se uma variação positiva nas exportações de café, sendo a mais expressiva no período de 1999/07. A participação das exportações brasileiras (market-share) no comércio mundial evolui de 16,8\% (primeiro período) para 16,6\% (segundo período) e 17,8\% (terceiro período). 
TABELA 4. TAXAS E FONTES DE CRESCIMENTO DAS EXPORTAÇÕES BRASILEIRAS DO COMPLEXO AGROINDUSTRIAL CAFEEIRO, EM \%

\begin{tabular}{l|c|c|c}
\hline \multirow{2}{*}{\multicolumn{1}{c}{ Indicadores / Complexo Cafeeiro }} & \multicolumn{3}{|c}{ Períodos } \\
\cline { 2 - 4 } & $\mathbf{1 9 9 0 - 1 9 9 3}$ & $\mathbf{1 9 9 4 - 1 9 9 8}$ & $\mathbf{1 9 9 9 - 2 0 0 3}$ \\
\cline { 2 - 4 } & $\mathbf{1 9 9 4 - 1 9 9 8}$ & $\mathbf{1 9 9 9 - 2 0 0 3}$ & $\mathbf{2 0 0 4 - 2 0 0 7}$ \\
\hline a) Taxas de crescimento & & & \\
\hline Exportações Mundiais & 93,3 & $(53,6)$ & 166,2 \\
\hline Exportações Brasileiras & 88,0 & $(53,4)$ & 191,0 \\
\hline Market-Share & 16,8 & 16,6 & 17,8 \\
\hline b) Fontes de crescimento & & & \\
\hline Crescimento do comércio mundial & 49,6 & $(115,1)$ & 57,1 \\
\hline Composição da pauta de exportações & $(0,1)$ & $(5,3)$ & $(5,1)$ \\
\hline Destino das exportações & $(2,1)$ & $(1,9)$ & $(3,1)$ \\
\hline Competitividade & 52,5 & 222,2 & 51,1 \\
\hline
\end{tabular}

Fonte: elaborado a partir dos dados da FAO e MDIC/SECEX, 2010.

A decomposição das fontes de crescimento das exportações brasileiras do complexo cafeeiro indicou que no primeiro período, 49,6\% das exportações de café foi atribuído ao efeito do crescimento do comércio mundial. O efeito competitividade foi responsável por $52,5 \%$ do comportamento das exportações, verificando-se: estabilidade da demanda nos mercados consumidores tradicionais, fator que contribuiu para o desempenho das exportações, pois o crescimento mundial foi responsável por $49,6 \%$ do comportamento das exportações, retração de 2,1\% no seu destino, além do fraco desempenho na composição da pauta de exportações.

No segundo período o desempenho foi ainda pior que no primeiro, pois não se pode contar com o crescimento do comércio mundial; houve o engessamento da pauta de exportação devido à persistência em explorar mercados saturados, conduzindo a uma excessiva dependência da competitividade dos fatores internos de produção para suportar a retração de mercado e a investida dos concorrentes.

A competitividade foi responsável pelo aumento das exportações; ela oscilou entre $51 \%$ a $222,2 \%$, em razão das cíclicas crises no período de estudo, contribuindo para despertar mudanças no setor cafeeiro e no destino das exportações de café brasileiro para novos mercados. Grande parte da competitividade verificada no período de 1999 a 2003 foi fruto da política cambial - a adoção do regime de câmbio flutuante - verificando-se significativa desvalorização do real perante as moedas fortes, e da recuperação da crise das economias asiáticas e do leste europeu, principalmente a russa. No período de estudo a competitividade e o crescimento do mercado mundial foram responsáveis pelo crescimento das exportações brasileiras do complexo agroindustrial cafeeiro. 
O crescimento efetivo das exportações brasileiras deve-se ao efeito da competitividade, o que retrata forte associação do desempenho das exportações brasileiras de café com o dinamismo do comércio internacional. $\mathrm{O}$ crescimento do comércio mundial e a abertura de novos mercados facilitaram a penetração do complexo agroindustrial brasileiro no mercado exterior. A pauta de exportações manteve-se concentrada no café verde e solúvel, indicando que a tendência de diversificação na composição da pauta de exportações ainda é pequena.

A análise do modelo CMS ressalta a fragilidade de políticas internas direcionadas à abertura de novos mercados e à divulgação do produto brasileiro no exterior. Durante o período em estudo, a competitividade e, no período recente (última fase), o crescimento do mercado internacional foram as principais fontes de crescimento das exportações do complexo agroindustrial brasileira.

O desempenho das exportações deste complexo também pode ser explicado pelo rompimento do Acordo Internacional do Café, a extinção do Instituto Brasileiro de Café, a abertura econômica, a entrada do Brasil no bloco econômico do Mercosul e a implantação do Plano Real. Tais fatores contribuíram para o declínio da participação do país no mercado internacional de café verde, em volume exportado e em parcela de mercado, nos primeiros anos da década de 1990, que repercutiu no resultado de todo o período, devido à perda de competitividade.

O crescimento efetivo das exportações brasileiras de café verde, entre 1990 e 1998, em parte podem ser atribuídos ao crescimento do comércio mundial, que apresentou valor positivo (50\%) (Tabela 5). O efeito destino das exportações foi negativo $(1,0 \%)$ indicando que este produto está sendo direcionado a mercado com pressão de oferta e requer redirecionamento de mercados e redução da oferta do produto nos mercados tradicionais das exportações brasileiras. 
SEREIA, V. J.; CAMARA, M. R. G.; ANHESINI, J. A. R. Competitividade do complexo cafeeiro...

TABELA 5. TAXAS E FONTES DE CRESCIMENTO DAS EXPORTAÇÕES BRASILEIRAS DE CAFÉ VERDE, EM \%

\begin{tabular}{l|c|c|c}
\hline \multirow{2}{*}{\multicolumn{1}{c}{ Indicadores / Café Verde }} & \multicolumn{3}{c}{ Períodos } \\
\cline { 2 - 4 } & $\mathbf{1 9 9 0 - 1 9 9 3}$ & $\mathbf{1 9 9 4 - 1 9 9 8}$ & $\mathbf{1 9 9 9 - 2 0 0 3}$ \\
\cline { 2 - 4 } & $\mathbf{1 9 9 4 - 1 9 9 8}$ & $\mathbf{1 9 9 9 - 2 0 0 3}$ & $\mathbf{2 0 0 4 - 2 0 0 7}$ \\
\hline a) Taxas de crescimento & & & \\
\hline Exportações Mundiais Café Verde & 92,0 & $(59,7)$ & 145,2 \\
\hline Exportações Brasileiras Café Verde & 84,4 & $(51,9)$ & 188,3 \\
\hline Market-Share & 18,5 & 19,3 & 24,5 \\
\hline b) Fontes de crescimento & & & \\
\hline Crescimento do comércio mundial & 49,9 & $(124,2)$ & 50,4 \\
\hline Destino das exportações & $(1,0)$ & $(1,9)$ & $(4,2)$ \\
\hline Competitividade & 51,1 & 226,2 & 53,8 \\
\hline Fonte: elaborado a partir dos dados da FAO e MDIC/SECEX, 2010.
\end{tabular}

O efeito competitividade foi $51 \%$ e de acordo com Resende (2001), pode estar associado à restrição da oferta, ao endividamento em geral do setor; à baixa capacidade de coordenação de seus agentes, para se adequarem ao novo padrão competitivo do mercado. Essa redução é refletida nas estatísticas que indicam declínio ou estagnação do consumo de café commodity tanto no mercado norte-americano como no europeu, maiores compradores do Brasil. Ao mesmo tempo, verifica-se o crescimento da demanda de cafés especiais, mas o Brasil apresenta dificuldades em atender tal demanda.

Apesar da drástica redução das exportações mundiais no segundo período terem influenciado negativamente a taxa de crescimento das exportações mundiais de café, o Brasil conseguiu ampliar o nível de participação das exportações (market-share) de café verde no mercado mundial de 19,3\%. Isso é resultado do efeito competitividade significativo (226,2\%) e com pouca influência negativa do efeito destino das exportações. No último período, o mercado mundial voltou a crescer aliviando a pressão aos países exportadores e desta forma o Brasil ampliou sua fatia de mercado (market-share) do café verde para $24,5 \%$, mas persistiu nos mercado concentrados, levando ao afrouxamento da competitividade $(53,8 \%)$, em função da retomada do crescimento do comércio mundial (50,5\%).

O mercado internacional de café processado, torrado e solúvel, é influenciado por políticas protecionistas dos países importadores, que resulta em competitividade desigual entre as empresas processadoras italianas, alemãs e americanas. A indústria brasileira não consegue atingir o patamar competitivo exigido pelo mercado, embora o parque industrial seja similar ao concorrente internacional, mas as barreiras e as estratégias da indústria alimentícia internacional impactam negativamente, afetando a parcela de mercado e os resultados dos cafés processados ao longo do período estudado. A prática do 
draw back (reexportação), principalmente pelos europeus, requer políticas de incentivos e facilidades à entrada de café verde para alimentar as indústrias processadoras.

A Tabela 6 apresenta os resultados da decomposição das exportações brasileiras de café solúvel. No primeiro período, as exportações de café solúvel cresceram puxadas pelo forte crescimento de $47,6 \%$ do comércio mundial e do efeito competitividade em $63,3 \%$, em uma conjuntura de crescimento das exportações mundiais, da posição favorável de 18,5\% do market-share. Nota-se que nos períodos subseqüentes a participação das exportações (market-share) brasileiras de café solúvel diminuiu no período estudado, de 15,8\% para 11,3\% no último período.

A redução das exportações brasileiras de café solúvel foi afetada pela retração do crescimento do comércio mundial - crises financeiras entre 1994 e 2002 da Ásia, Rússia, Brasil e Argentina, da crise derivada do ataque às "torres gêmeas" nos EUA - e pelas barreiras protecionistas nos EUA e na Comunidade Européia e a forte desvalorização do real não evitou a redução da competitividade das exportações de $178,3 \%$ para $38,2 \%$ no período mais recente. (Giambiagi et. al., 2004)

TABELA 6. TAXAS E FONTES DE CRESCIMENTO DAS EXPORTAÇÕES BRASILEIRAS DE CAFÉ SOLÚVEL, EM \%

\begin{tabular}{l|c|c|c}
\hline \multirow{2}{*}{\multicolumn{1}{c}{ Indicadores / Café Solúvel }} & \multicolumn{3}{|c}{ Períodos } \\
\cline { 2 - 4 } & $\mathbf{1 9 9 0 - 1 9 9 3}$ & $\mathbf{1 9 9 4 - 1 9 9 8}$ & $\mathbf{1 9 9 9 - 2 0 0 3}$ \\
\cline { 2 - 4 } & $\mathbf{1 9 9 4 - 1 9 9 8}$ & $\mathbf{1 9 9 9 - 2 0 0 3}$ & $\mathbf{2 0 0 4 - 2 0 0 7}$ \\
\hline a) Taxas de crescimento & & & \\
\hline Exportações Mundiais & 100,3 & $(35,9)$ & 192,3 \\
\hline Exportações Brasileiras & 110,8 & $(62,5)$ & 202,6 \\
\hline Market-Share & 18,5 & 15,8 & 11,3 \\
\hline b) Fontes de crescimento & & & \\
\hline Crescimento do comércio mundial & 47,6 & $(95,6)$ & 63,5 \\
\hline Destino das exportações & $(10,9)$ & 17,2 & $(1,8)$ \\
\hline Competitividade & 63,3 & 178,3 & 38,3 \\
\hline
\end{tabular}

Fonte: elaborado a partir dos dados da FAO e MDIC/SECEX, 2010.

A análise do modelo CMS permitiu verificar que há falhas nas políticas e estratégias internas para abertura de novos mercados no exterior. Embora a participação das exportações brasileiras de café solúvel venha crescendo, existe muita dificuldade em imprimir um ritmo de crescimento acelerado diante dos concorrentes europeus e norte-americano. A competitividade e o crescimento do comércio mundial foram as principais fontes de crescimento das exportações brasileiras de café solúvel. 
Na Tabela 7 aparecem os resultados da decomposição das exportações brasileiras de café torrado, mostrando seu crescimento diferenciado ao longo do período estudado. O desempenho indica que as exportações foram influenciadas pelas crises da economia mundial no final da década de 1990.

A participação das exportações brasileiras (market-share) de café torrado no comércio mundial foi crescente em todo período analisado, mas ainda é muito baixa, não tendo alcançando 1,0\% das exportações mundiais. Isto demonstra que este produto pode ser melhor explorado pela indústria nacional; a análise dos resultados permite verificar que as principais fontes de crescimento das exportações no primeiro período são atribuídas ao efeito da competitividade $(61,4 \%)$ e ao favorável crescimento do comércio mundial (35.3\%).

TABELA 7. TAXAS E FONTES DE CRESCIMENTO DAS EXPORTAÇÕES BRASILEIRAS DE CAFÉ TORRADO, EM \%

\begin{tabular}{l|c|c|c}
\hline \multirow{2}{*}{\multicolumn{1}{c}{ Indicadores / Café Solúvel }} & \multicolumn{3}{c}{ Períodos } \\
\cline { 2 - 4 } & $\mathbf{1 9 9 0 - 1 9 9 3}$ & $\mathbf{1 9 9 4 - 1 9 9 8}$ & $\mathbf{1 9 9 9 - 2 0 0 3}$ \\
\cline { 2 - 4 } & $\mathbf{1 9 9 4 - 1 9 9 8}$ & $\mathbf{1 9 9 9 - 2 0 0 3}$ & $\mathbf{2 0 0 4 - 2 0 0 7}$ \\
\hline a) Taxas de crescimento & & & \\
\hline Exportações Mundiais & 92,5 & $(28,4)$ & 231,9 \\
\hline Exportações Brasileiras & 162,0 & 25,8 & 469,9 \\
\hline Market-Share & 0,2 & 0,3 & 0,6 \\
\hline b) Fontes de crescimento & & & \\
\hline Crescimento do comércio mundial & 35,3 & $(22,6)$ & 40,7 \\
\hline Destino das exportações & 3,3 & $(0,3)$ & 2,7 \\
\hline Competitividade & 61,4 & 122,9 & 56,6 \\
\hline
\end{tabular}

Fonte: elaborado a partir dos dados da FAO e MDIC/SECEX, 2010.

No segundo período, os efeitos crescimento do comércio mundial e destino das exportações inibem o crescimento das exportações brasileiras, enquanto o aumento da competitividade (123\%) age de forma a compensar e a elevar a participação das exportações brasileiras no mercado mundial. A baixa participação brasileira na exportação de café torrado no início dos anos 90 e a forte proteção internacional para os cafés processados afetam a indústria brasileira e o crescimento do comércio mundial apresenta-se como maior fonte de explicação do crescimento das exportações desse produto. 
A estratégia da indústria do café torrado e moído busca atender o mercado interno e a exportação aos países da América do Sul - Argentina, Uruguai e Chile. Conforme a Tabela 7, o crescimento das exportações tem se beneficiado do crescimento do comércio mundial e da competitividade da indústria nacional. Mesmo nos períodos de crise houve crescimento do market-share de 0,3 para $0,6 \%$, no período mais recente. A necessidade de diferenciação e a busca por novos produtos alternativos ao café torrado e moído tradicional induzem a indústria a ofertar o café torrado descafeinado, atendendo a um consumidor mais exigente e com restrições à ingestão de cafeína.

A Tabela 8 apresenta o desempenho das exportações de bebidas preparadas e essências de café. A oferta não é regular e contínua durante os períodos estudados, pois são produtos novos que se encontram em fase de afirmação nos mercados internacionais.

A comercialização de bebidas e essências é pouco representativa e o market-share é inferior a 1,0\%. No segundo período, o mercado torna-se mais competitivo devido às crises internacionais e ao mercado externo retraído.

TABELA 8. TAXAS E FONTES DE CRESCIMENTO DAS EXPORTAÇÕES BRASILEIRAS DE BEBIDAS E ESSÊNCIAS DE CAFÉ, EM \%

\begin{tabular}{l|c|c|c}
\hline \multirow{2}{*}{\multicolumn{1}{c}{ Indicadores / }} & \multicolumn{3}{c}{ Períodos } \\
\cline { 2 - 4 } \multicolumn{1}{c}{ Bebidas e essências de café } & $\mathbf{1 9 9 0 - 1 9 9 3}$ & $\mathbf{1 9 9 4 - 1 9 9 8}$ & $\mathbf{1 9 9 9 - 2 0 0 3}$ \\
\cline { 2 - 4 } & $\mathbf{1 9 9 4 - 1 9 9 8}$ & $\mathbf{1 9 9 9 - 2 0 0 3}$ & $\mathbf{2 0 0 4 - 2 0 0 7}$ \\
\hline a) Taxas de crescimento & & & \\
\hline Exportações Mundiais & 274,9 & $(44,7)$ & 84,2 \\
\hline Exportações Brasileiras & 140,7 & $(48,0)$ & 263,3 \\
\hline Market-Share & 0,4 & 0,3 & 0,5 \\
\hline b) Fontes de crescimento & & & \\
\hline Crescimento do comércio mundial & 114,2 & $(85,9)$ & 23,2 \\
\hline Destino das exportações & $(78,6)$ & 36,8 & 22,0 \\
\hline Competitividade & 64,5 & 149,2 & 54,8 \\
\hline
\end{tabular}

Fonte: elaborado a partir dos dados da FAO e MDIC/SECEX, 2010.

No período mais recente há a retomada do crescimento do comércio mundial, das exportações e a ampliação de mercados de destino. O market-share amplia-se e reforça a importância dos novos produtos para a indústria cafeeira brasileira. 
A Tabela 9 apresenta os resultados do modelo da vantagem comparativa revelada simétrica para o complexo cafeeiro brasileiro. As exportações brasileiras de café verde apresentam vantagens comparativas crescentes e as de café solúvel apresentam vantagens comparativas, mas elas declinam no período analisado. As vantagens do café verde e solúvel corrobora os resultados do modelo Constant Market Share.

O Brasil não tem tradição na exportação de café torrado e sua indústria não está ajustada aos padrões de consumo internacional, diferentemente das indústrias da Alemanha e da Itália, especializadas na oferta de produtos de primeira linha, ajustados ao paladar dos consumidores estrangeiros exigentes. O índice VCRS do café torrado brasileiro não revelou vantagem comparativa durante toda a série analisada, embora o país seja um grande produtor e exportador de café. Os dados de bebidas com café são excluídos do modelo VCRS por não apresentarem resultados mundiais individuais.

TABELA 9. BRASIL; EVOLUÇÃO VCRS DO COMPLEXO CAFEEIRO

\begin{tabular}{c|c|c|c|c}
\hline Períodos & Verde & Solúvel & Torrado & Total \\
\hline 1990 & 0,89 & 0,90 & $-0,95$ & 0,90 \\
\hline 1991 & 0,92 & 0,87 & $-0,78$ & 0,92 \\
\hline 1992 & 0,90 & 0,87 & $-0,36$ & 0,91 \\
\hline 1993 & 0,89 & 0,90 & $-0,84$ & 0,91 \\
\hline 1994 & 0,90 & 0,91 & $-0,77$ & 0,92 \\
\hline 1995 & 0,89 & 0,92 & 0,56 & 0,91 \\
\hline 1996 & 0,90 & 0,91 & $-0,55$ & 0,92 \\
\hline 1997 & 0,91 & 0,89 & $-0,67$ & 0,92 \\
\hline 1998 & 0,91 & 0,87 & $-0,70$ & 0,92 \\
\hline 1999 & 0,93 & 0,88 & $-0,72$ & 0,93 \\
\hline 2000 & 0,91 & 0,86 & $-0,61$ & 0,92 \\
\hline 2001 & 0,92 & 0,84 & $-0,44$ & 0,93 \\
\hline 2002 & 0,92 & 0,82 & $-0,40$ & 0,93 \\
\hline 2003 & 0,92 & 0,82 & $-0,14$ & 0,93 \\
\hline 2004 & 0,92 & 0,83 & $-0,44$ & 0,93 \\
\hline 2005 & 0,92 & 0,83 & $-0,29$ & 0,93 \\
\hline 2006 & 0,92 & 0,81 & $-0,19$ & 0,93 \\
\hline 2007 & 0,91 & 0,81 & $-0,28$ & 0,92 \\
\hline
\end{tabular}

Fonte: elaborado a partir dos dados da FAO e MDIC/SECEX, 2010. 
O café solúvel brasileiro apresentou perda de vantagem comparativa no período analisado, devido a dois fatores: estar na contramão da demanda mundial, que tem exigido preços competitivos, e enfrentar barreiras nos países desenvolvidos. Porém, o café verde ampliou a sua vantagem comparativa em todo o período, devido à grande diversidade de café no país. O Brasil oferta grande quantidade de café do tipo arábica, do tipo mais suave.

O complexo cafeeiro brasileiro tem procurado diversificar sua pauta de exportação com a criação de novos produtos e subprodutos de café. No entanto, o país ainda não tem tradição na exportação de bebidas, essências e extratos de café.

A participação brasileira foi afetada no mercado mundial de café, em parte, pela política de valorização de preços praticada pelo país; pela regulação do mercado, que ocorreu no período dos Acordos Internacionais; pelos momentos de valorização da moeda nacional, fazendo com que o Brasil reduzisse sua cota de exportação e estimulando a produção dos países concorrentes; e pela falta de políticas de coordenação e incentivos ao setor. O endividamento do setor, perda de qualidade do café brasileira (brasileiro), ausência de marketing externo, melhor divulgação do produto e aumento do consumo interno também justificam a perda de dinamismo do produto no mercado internacional (Saes; Nakazone, 2002; Nishijima; Saes, 2008, 2010).

\section{Conclusão}

O Brasil tem ocupado a posição de maior produtor e exportador mundial de café. O market-share das exportações brasileiras do complexo cafeeiro tem se mantido em média de $17 \%$, o que garante ao Brasil a hegemonia na oferta mundial de café. Os principais tipos de café exportado são: café verde, café solúvel, café torrado e bebidas e essências de café.

A Alemanha, Itália e os Estados Unidos são os principais países de destino das exportações de café verde, que além do consumo interno, serve de matéria prima para suas indústrias que os transformam em grandes exportadores de café torrado, solúvel e de bebidas com café. O Brasil é um grande exportador de café solúvel para os mercados da Rússia (19,1\%), da Ucrânia $(8,6 \%)$, dos Estados Unidos (13,1\%) e do Japão (5,9\%). A demanda do café torrado brasileiro é formada pelos mercados dos Estados Unidos (64,1\%), do Japão (5,0\%) e dos países do Mercosul (4,5\%). As exportações de bebidas e essência de café, ainda são de pouca expressão; o produto brasileiro atende aos mercados japoneses (42\%) e argentinos (8.2\%).

A evolução da participação das exportações brasileiras (market-share) de produtos processados foi influenciada por políticas protecionistas. 
A partir de 1995 as seguida e sucessivas crises financeiras internacionais abalaram o crescimento da economia internacional, promovendo o redirecionamento dos fluxos de capitais mundiais. O comércio mundial se retraiu e as exportações brasileiras do setor cafeeiro foram sustentadas por estratégias internas com base nos custos dos fatores de produção, abertura de novos mercados externos e crescimento da competitividade comercial.

A competitividade das exportações de café verde brasileiro foi essencial para garantir a participação no comércio mundial em função da crescente oferta da commodity principalmente, pelos países asiáticos e africanos. As exportações de café solúvel brasileiras perderam substantiva participação e simultaneamente, ocorreu alguma desconcentração dos países de destino.

A exportação de café torrado aumentou a participação no comércio mundial, sustentada pelo ganho de competitividade, mas ainda são inexpressivas diante da demanda mundial. As exportações brasileiras de bebidas e essências com café se mantiveram concentradas em um reduzido número de países de destino. A característica marcante no comércio mundial de café é a concentração do comércio por especialidade ou tipo de café, enquanto os países produtores são grandes exportadores da commodity e apresenta pouca reação a transformação em novos produtos, valorizados no mercado, os países industriais se firmam como grandes exportadores de produtos diferenciados.

O VCRS confirmou a capacidade competitiva do complexo cafeeiro brasileiro, sustentado pela vantagem competitiva do café verde e solúvel, corroborando os resultados do modelo CMS. O Brasil não apresentou vantagem competitiva no café torrado, dada a baixa capacidade das empresas brasileiras de ofertarem o produto com a qualidade dentro dos padrões exigidos pelo mercado internacional.

As alterações ocorridas no comércio mundial de café durante o período analisado indicaram a necessidade de ampliar mercados, melhorar a qualidade do café - em particular no processamento do café verde - e lançar novos produtos, além do café torrado e bebidas contendo café e novas essências de café; o resultado dos esforços inovativos pode contribuir para agregar valor, criar empregos, gerar renda internamente e obter melhores preços para o produto do complexo cafeeiro no mercado internacional. A produção nacional deve se adequar às novas tendências do consumo mundial, pois a demanda internacional se voltado para produtos com forte apelo à preservação ambiental, a exemplo do café orgânico. A ampliação dos incentivos à inovação de processos e produto na cadeia cafeeira, cujo foco é o setor exportador, poderá compensar a perda de competitividade derivada da imposição de barreiras ao café brasileiro. A despeito dos esforços bem sucedidos no sentido de integrar a cadeia cafeeira com sucesso, há necessidade de melhorias na infra-estrutura de transporte, de forma a contribuir para a redução dos custos e incremento nos lucros dos exportadores do complexo cafeeiro. 


\section{Referências bibliográficas}

ABIC - Associação Brasileira de Indústria de Café. (2011). URL [on-line]: <http://www.abic.com.br/publique/cgi/cgilua.exe/sys/start.htm?sid=49>.

AMARAL, S. (2001). "Café requentado”. Folha de São Paulo.

BIELSCHOESKY, R.; STUMPO, G. (1996). "A internacionalização da indústria brasileira: números e reflexões depois de alguns anos de abertura”. In: BAUMANN, R. (1996). O Brasil e a economia global. Rio de Janeiro: Campus.

BRAGANÇA, G. G. F. (200o). Poder de mercado do café brasileiro nos EUA: abordagem via demanda residual. Dissertação Mestrado. Rio de Janeiro: Faculdade Getúlio Vargas (FGV/RJ).

CARVALHO, F. M. A. (1995). O comportamento das exportações brasileiras e a dinâmica do complexo agroindustrial. [Tese Doutorado]. Piracicaba: Escola Superior de Agronomia Luiz de Queiroz (Esalq/USP).

CARVALHO, M. A.; SILVA, C. R. L. (2000). Economia internacional. SP: Saraiva.

CASTRO, A. M. G.; LIMA, S. M. V.; HOEFLICH, V. A. (2002). Cadeias produtivas. Curitiba: Instituto de Tecnologia do Paraná (TECPAR).

Conselho dos Exportadores de Café (Cecafé). Informações gerais.URL [on-line]: <http://www.cecafe.com.br>. Acesso em: 23/11/2010.

COUTINHO, L.; FERRAZ, J. C. (1994). Estudo da competitividade da indústria brasileira. Campinas: Papirus.

DUNNING, J. (1988). "The ecletic paradigm of international production: a reestatment and some possible extensions." Journal of international Marketing Business Studies, vol. 19 (1), p.1-31.

Embaixada do Brasil em Washington (2002). "Barreiras aos produtos e serviços brasileiros". Washington.

FAO - Food and Agriculture Organization of United Nations. URL [on-line]: $<$ http://faostat.fao.org/default.aspx>. Acesso em: novembro de 2010.

FERRAZ, J. C.; KUPFER, D.; HAGUENAUER, L. (1995). Made in Brazil: desafios competitivos para a indústria. Rio de janeiro: Campus.

GIAMBIAGI, F.; VILLELA, A.; CASTRO, L. B.; HERMANN, J. (1998). Economia Brasileira Contemporânea. Rio Janeiro: Campus, 2004.

GONÇALVES, R. et al. (1998). A nova economia internacional: uma perspectiva brasileira. Rio de Janeiro: Campus.

GONÇALVES, R. (1996). "Globalização financeira, liberalização cambial e vulnerabilidade externa da economia brasileira”. In: BAUMANN, R. (1996) O Brasil e a economia global. Rio de Janeiro: Campus.

GRASSI, R. A. (1997). “Comentários sobre a aplicação empírica do conceito estrutural de competitividade”. Leituras de Economia Política, vol. 04.

GUIMARÃES, E. P. (1997). "Evolução das teorias de comércio internacional”. Estudos em Comércio Exterior, I (2). ECEX/IE/UFRJ.

ICO - International Coffe Organization (2010). Informações gerais. URL [on-line]: <http://www.ico.org/trade_statistics.asp>. Acesso em: novembro de 2010. 
KENEN, P. B. (1998). Economia internacional: teoria e política. RJ: Campus.

KRUGMAN, P.; OBSTFELD, M. (1999). Economia internacional. Makron Books.

KUPFER, D. (1992). “Padrões de concorrência e competitividade”. In: Anais do XX Encontro Nacional de Economia. Campos do Jordão.

LEAMER, E. E.; STERN, R. M. (1970). “Constant-market-share analysis of export growth”. Quantitative international economics, vol. 07. Boston: Allyn \& Bacon.

MAIA, J. M. (1998). Economia internacional e comércio exterior. São Paulo: Atlas.

MDIC - AliceWeb; Ministério da Indústria e do Comércio. URL [on-line]: <http://aliceweb.desenvolvimento.gov.br>. Acesso em: novembro de 2010.

NISHIJIMA, M.; SAES, M. S. M. (2008). “Análise econômica das barreiras tarifárias ao café solúvel brasileiro”. In: XLVI Congresso da SOBER.

NISHIJIMA, M.; SAES, M. S. M. (2010). “Tariff discrimination on Brazil's soluble coffee: an economic analysis”. Revista de Economia Política, vol. 30 (2).

ORMOND, J. G. P.; PAULA, S. R. L.; FAVERET FILHO, P. (1999). “Café: (Re) conquista dos mercados”. BNDES Setorial, vol. 10. Rio de Janeiro.

PORTER, M. E. (1986). Estratégia competitiva: técnicas para análise de indústrias e da concorrência. Rio de Janeiro: Campus.

RESENDE, R. M. (2001). Relações entre o Mercosul e as exportações brasileiras de café. Dissertação Mestrado. Viçosa: Universidade Federal de Viçosa (UFV).

RICARDO, D. (1982). Princípios de economia política e tributação. Abril Cultural.

SAES, M. S. M.; NAKAZONE, D. (2002). “Cadeia: café”. Estudo da Competitividade das Cadeias Produtivas Integradas no Brasil: impacto do livre comércio. Campinas: Universidade Estadual de Campinas (Unicamp).

SALVATORE, D. (2000). Economia internacional. Rio de Janeiro: LTC.

STALDER, S. H. G. M. (1997). Análise da Participação do Brasil no Mercado Internacional de Açúcar. Dissertação de Mestrado em Economia. Piracicaba: Escola Superior de Agricultura Luiz de Queiroz (Esalq/USP).

TEIXEIRA, T. D. (2000). "Política estratégica para a cafeicultura brasileira". In: I Simpósio de Pesquisa dos Cafés do Brasil, vol. 01 (1), p. 169-193.

WEDECKIN, I. (2002). "Os agriclusters e a construção da competitividade local”. Anais do I Congresso Brasileiro de Agribusiness, vol. 01, p. 43-55.

WILLIAMSON, J. (1989). A economia aberta e a economia mundial: um texto de economia internacional. Rio de Janeiro: Campus.

Recebido em: 03 de outubro de 2010 Primeira resposta em: 09 de novembro de 2010 Aceite em: 28 de abril de 2011 
SEREIA, V. J.; CAMARA, M. R. G.; ANHESINI, J. A. R. Competitividade do complexo cafeeiro... 